\title{
Ventilation Performance Investigation of Roof Top Solar Chimney
}

\author{
Tamerat Demeke Agonafer
}

Mechanical Engineering Department, Debre Berhan University, Debre Berhan, Ethiopia

\section{Email address:}

tamrat20@gmail.com

\section{To cite this article:}

Tamerat Demeke Agonafer. Ventilation Performance Investigation of Roof Top Solar Chimney. American Journal of Mechanical and Industrial Engineering. Vol. 5, No. 2, 2020, pp. 15-23. doi: 10.11648/j.ajmie.20200502.11

Received: May 21, 2020; Accepted: June 9, 2020; Published: June 23, 2020

\begin{abstract}
The solar chimney is an innovation, which has been as of now demonstrated of being able to create electrical vitality from the sun likewise it has been introduced in different structures for ventilation, and next to no is thought about their genuine presentation and very panics are the application. This research work deals with the development of a physical, mathematical and computational models of roof solar chimney to rationalize the performance of ventilate in residential house. A thermal model enables to easily determine the inclination angle, absorber area, cavity width of the chimney and the air flow rate, using MATLAB. The simulation has been done for selected residential house of $264 \mathrm{~m}^{3}$ located at Bahir Dar city, Ethiopia (a) $11^{\circ}$ latitude and $37^{\circ}$ longitude. At comfort air speed $(2 \mathrm{~m} / \mathrm{s})$, a south faced system being tilted at an angle of $45^{\circ}$ will have absorber length, the absorber height and cavity width about $3 \mathrm{~m}, 4.24 \mathrm{~m}$, and $0.5 \mathrm{~m}$ respectively. This will enable the residential house to circulate the air $560 \mathrm{~kg}$ per hour. The maximum air temperature obtained at chimney outlet is $44.5^{\circ} \mathrm{C}$. For a month of April an average solar intensity value is $900 \mathrm{~W} / \mathrm{m}^{2}$. The main factor to induce buoyancy is solar insolation since it directly influences the air temperature, and the efficiency is about $44.4 \%$.
\end{abstract}

Keywords: Air Change Rate, Natural Ventilation, Solar Chimney Performance, Solar Insolation

\section{Introduction}

Nowadays people spent most of their time on working and living in buildings, therefore ventilation is very important to maintain the indoor environment in a good air quality and temperature. In order to achieve this, solar chimney is cleaver device and has been employed in a building using sustainable energy source (Sun) to heat up the air temperature. Solar chimney works in the physical phenomenon of buoyancy, in this case located on the top of the roof. The possible size (height, width and cavity width) will estimate using simulation. The front is a transparent glass and the remaining faces are blacked out to absorb heat. Thus, converting solar energy into kinetic energy of air to heat and move upward in the channel to create natural draft. Therefore, chimney system has the potential advantages over mechanical ventilation systems in terms of benefits of environmentally friendly and energy cost. Prior research tries to indicate solar chimney concepts as a means of passive building ventilation, [3]. In their study presented the study of Experiment and CFD simulation and conclude how solar chimney is suitable to achieve natural ventilation with good performance [8], studied mathematical and numerical modeling airflow model of the solar chimney in the cooling tube and solar chimney system has been developed. [11], Modeling natural convection in a heated vertical channel for room ventilation, Building and Environment studied using experimental and mathematical modeling, results that buoyant airflow within the chimney is possible and the variation of air temperature elevation with insolation is minimal while the chimney gives better performance where lower values of solar radiation. [14], Thermal performance of atria: An overview of natural ventilation effective design and simulation on eight story office building, experimental model and CFD simulation of atrium with a medium size outlet of $5.2 \mathrm{~cm}$ and a small inlet size of $2 \mathrm{~cm}$ has becomes the most effective configuration with regards to the ventilation rate in the proposed office building. [17], study effective solar chimney cross section and simulation result gives effective width gap for $36 \mathrm{~m}^{3}$ room ranged from $0.6 \mathrm{~m}$ to $1.0 \mathrm{~m}$ while the length from $1.5 \mathrm{~m}$ to $2.0 \mathrm{~m}$, then results the induced air speed ranged from $0.04 \mathrm{~m} / \mathrm{s}$ to $0.223 \mathrm{~m} / \mathrm{s}$. Studies demonstrate the using of solar 
chimney and declaring that solar chimney can provide air flow and get adequate natural ventilation in a building. Prior researches need modification in order to implement in already existing buildings and also in Ethiopia it is not common practice designed a building with which natural air circulation. The main objective of this research is to develop mathematical model of solar powered buoyancy driven solar chimney subjected to the demands of the villa house ventilation with total size of $264 \mathrm{~m}^{3}$. Also, use of solar chimney is suggested a modification as a roof top system, to achieve this that mathematical model is established and presented based on energy and mass conservation.

\section{Methodologies}

System design is started by studying the possibilities how solar chimney is integrated to the existing building and look the effect of each parameter of solar chimney sensitivity to the performance during steady state condition in the first stages, Figure 1 shows the flow diagram of the project procedure. The parametric examinations utilized the basic climate information condition for Bahir Dar city and acquired from the run of the mill meteorological year (TMY) informational collections of NASA, SWERA, NMSA just as surface metrology and sun based vitality database (SMSE), so that the ambient temperature is $34^{\circ} \mathrm{C}$, relative humidity is $17 \%$ and solar irradiation of $900 \mathrm{~W} / \mathrm{m}^{2}$ during hottest period. So, that in $2^{\text {nd }}$ and $3^{\text {rd }}$ stage intensions are to study different parameters that achieve compact and high-performance system, books, journals and articles are reviewed in solar ventilation technology to know current practice in different countries. In $4^{\text {th }}$ stage detail thermal analysis will be performed for physically modeled solar chimney structure to determine the thermal response of the system; this were solved numerically by using Gauss- Seidel iterative method implemented in MATLAB. The program calculates the chimney outlet air temperature, mass flow rate/volume flow rate, air change rate and system efficiency. In last stage simulation results are discus how the solar chimney length, width and solar intensity affects the performance. Followed by recommendations for further study and indication of practical implementation.

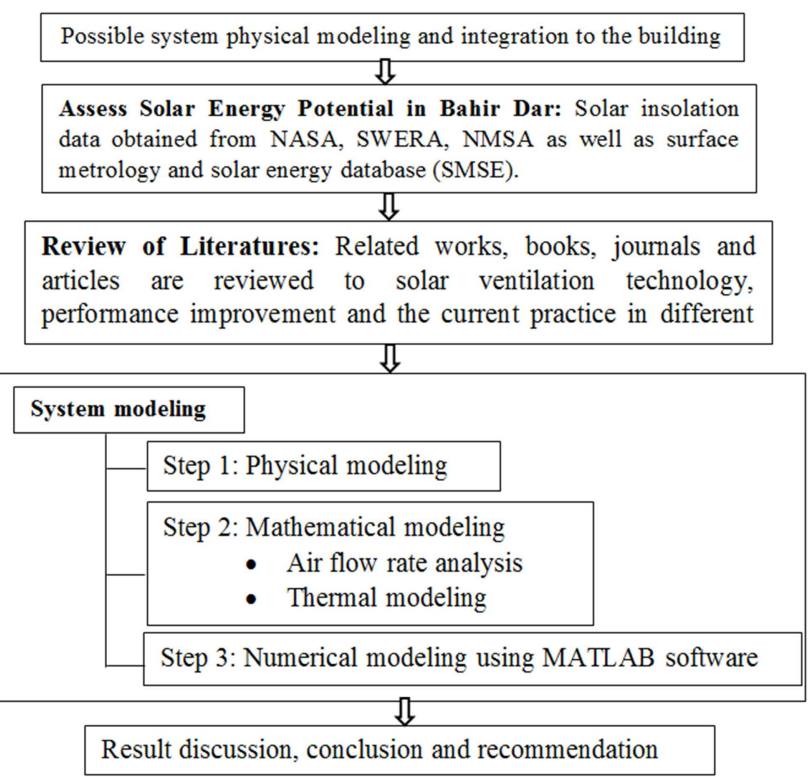

Figure 1. Flow diagram of project procedure.

\section{Physical Modeling}

The proposed physical modeling describes the working principles of solar chimney installed on the roof of the building. For this innovation the chimney differs with conventional one in that at least one face is made transparent to allow solar radiation enters and heats up the black absorber surface. The temperature of the air inside the solar chimney channel rises due to heat transfer from the black surface wall and resulting buoyancy and drives the airflow through the channel. The chimney pulls air from inside building and replaced by fresh air through doors, windows or vents. The inclination angle of solar chimney and installation possibilities (shown in Figure 2) influences the ventilation rate efficiency. In the present research, the effect of $45^{\circ}$ sloped solar chimney has been examined in examined.

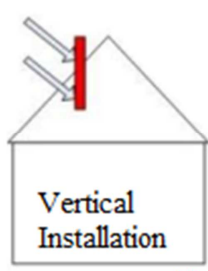

(a)

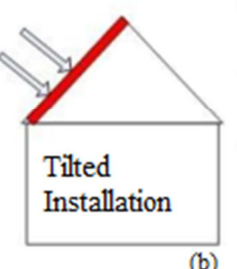

(b)

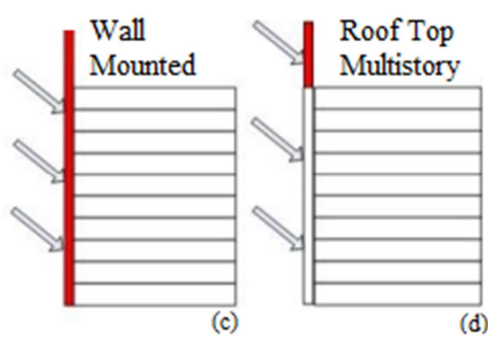

(d)

Figure 2. Solar chimney Installation Possibilities and proper location in a Buildings (gash 1955).

The proposed schematic assembly drawing of the solar chimney integrated with the building is presented in Figure 3, the air enters to the chimney through a bottom inlet from living space, the air then absorbs energy inside the solar chimney and heated up by convection, finally, the air exits to produce flow from living space to the outdoor due to buoyancy effect.

The geometry of the solar chimney cross section (Figure 4) described by its height, length and cavity width and this are the critical parameters to optimize the effective dimension to determine the performance of the system with recommended air change rate. 


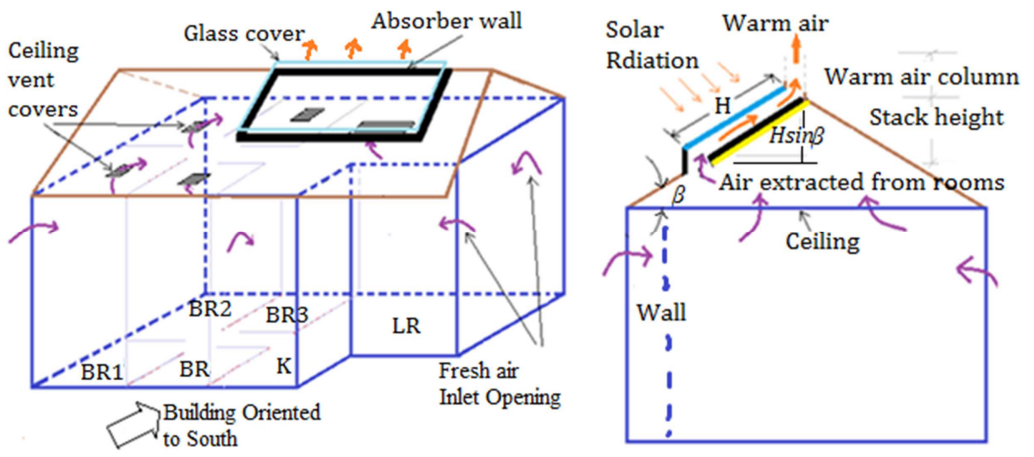

Figure 3. Schematic and side view of solar chimney subjected for ventilation of residential.
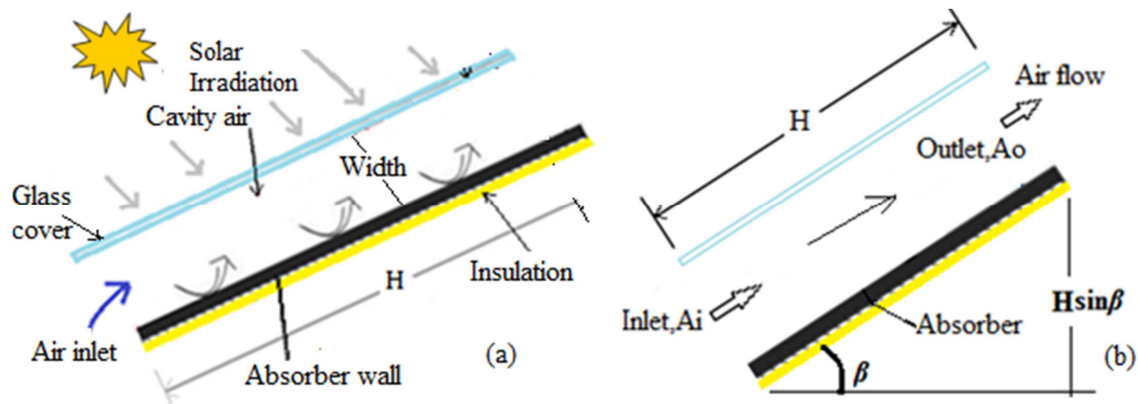

Figure 4. (a) Solar chimney components, (b) Solar chimney cross section and parameters.

\section{Mathematical Modeling and Parametrization}

\section{Thermal Modeling}

The main objective of the mathematical model is determining the temperature of glass $T g$, absorber wall $T w$ and air $T f$, to determine effective dimensions of the chimney, to predict comfortable air speed and to predict the performance of the chimney. Energy and mass balance equations are used for the analysis of the system given by: using thermal and mass balance. and can be seen as in the case of a compressible Newtonian fluid.

$$
\frac{d m_{C V}}{d t}=\sum_{\text {in }} \dot{m}-\sum_{\text {out }} \dot{m}
$$

And;

$$
\frac{k}{C \rho} \frac{\partial T}{\partial t}=\frac{\dot{q}}{k}+\left(\frac{\partial T}{\partial x}+\frac{\partial T}{\partial y}+\frac{\partial T}{\partial z}\right) \cdot \vec{\nabla}
$$

During mathematical modeling the following assumptions are made; the flow is steady state and one dimensional and the velocity $\mathrm{V}$ and density $\rho$ are constant over the area. The air flow rate at the outlet opening for uniform air temperature at which mass is flowing in and out of a control volume, setting the net in-flow equal to the rate of change of mass through the solar chimney analyzed with the assumption, $m$ is the air mass flow rate $(\mathrm{kg} / \mathrm{s})$ that crosses the system as $[5,11]$ explored the expression;

$$
\dot{m}=C_{d} \rho_{o} A_{o} \sqrt{\frac{2 g H \sin \beta\left(T_{f}-T_{r}\right)}{\left[1+\left(A_{r}\right)^{2}\right] T_{r}}}
$$

The volumetric air flow rate is thus:

$$
V=C_{d} A_{o} \sqrt{\frac{2 g H \sin \beta\left(T_{f}-T_{r}\right)}{2 T_{r}}}
$$

Where: $A_{r}=A_{o} / A_{o}$, but since the system has similar inlet outlet cross section the ratio is unity.
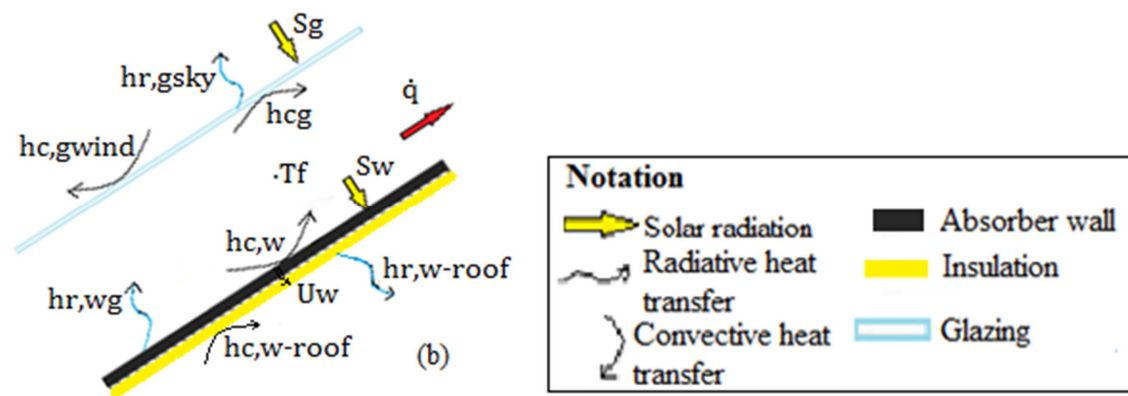

Figure 5. Solar energy pathway (heat transfer process).

Then writing thermal (energy) balance equation for each component of solar chimney as Figure 5; 
At the glass:

$$
h_{r, w g}\left(T_{w}-T_{g}\right)+h_{c, f g}\left(T_{f}-T_{g}\right)=h_{r, g s k y}\left(T_{g}-T_{s k y}\right)+h_{c, g w i n d}\left(T_{g}-T_{a m b}\right)
$$

Solving for $T_{g}$,

$$
=\frac{h_{r, w g} T_{w}+h_{c, f g} T_{f}+h_{r, g s k y} T_{s k y}+h_{c, g w i n d} T_{a m b}}{h_{r, g s k y}+h_{c, g w i n d} h_{r, w g} h_{c, f g}}
$$

At the absorber wall:

$$
S_{w}=h_{r, w g}\left(T_{w}-T_{g}\right)+h_{c, w f}\left(T_{w}-T_{f}\right)+U_{w}\left(T_{w}-T_{a m b}\right) S_{w}=h_{r, w g}\left(T_{w}-T_{g}\right)+h_{c, w f}\left(T_{w}-T_{f}\right)+U_{w}\left(T_{w}-T_{a m b}\right)
$$

Solving for $T_{w}$,

$$
=\frac{S_{w}+h_{r, w g} T_{g}+h_{c, w f} T_{f}-\frac{k}{2 \Delta x}\left(T_{-1, w}-T_{l+1, w}\right)}{\left(h_{r, w g}-h_{c, w a}\right)}
$$

At the air at the cavity.

$$
h_{c, w-f}\left(T_{w}-T_{f}\right)+\dot{q}_{a i r}=h_{c, f-g}\left(T_{f}-T_{g}\right)
$$

Solving for $T_{f}$,

$$
=\frac{h_{c, w f} T_{w}+\dot{q}_{a i r}+h_{c, f g} T_{g}}{h_{c, w f}+h_{c, f g}}
$$

The temperature of the absorber wall, the glass cover and the air along the flow channel, are determined by arranging $(4,5,6)$ respectivley in a matrix form. Where solved numerically using Gauss- Seidel iterative method implemented in MATLAB software, expressed by. $[\mathrm{A}][\mathrm{T}]=[\mathrm{B}]$

Coefficents of various convective, conductive and radiative heat transfer terms calculated as;

Convective heat transfer coefficients between absorber wall and air:

$$
h_{c, w-f}=\frac{N_{u} \cdot k}{L}
$$

Convective heat transfer coefficient from air to glass cover:

$$
h_{c, f-g}=\frac{N_{u} \cdot k}{L}
$$

Equation (8 and 9) then compute based on Nusselt number which itself is get through experimental correlation and depends on the Rayleigh $R a$ and Prandtl $\mathrm{Pr}$ number. Churchill and Chu have recommended the following correlation, which may be applied over the entire range of $R a$ :

When; $0<R a<10^{9}$ the flow is laminar and Nusselt number has the form:

$$
N_{u}=0.68+\frac{0.67(R a)^{1 / 4}}{\left[1+(0.492 / P r)^{9 / 16}\right]^{4 / 9}}
$$

When; $R_{a}>10^{9}$ the flow is turbulent and Nusselt number has the form:

$$
N_{u}=\left[0.825+\frac{0.387(R a)^{1 / 4}}{\left[1+(0.492 / P r)^{9 / 16}\right]^{8 / 27}}\right]^{2}
$$

Where:

$$
R a=\frac{g \beta\left(T_{r}-T_{f}\right) L^{3}}{\alpha v}
$$

$$
\operatorname{Pr}=\frac{C_{p, a} \cdot \mu_{a}}{k_{a}}
$$

Where: $v=\frac{\mu_{a}}{\rho_{a}}, \alpha=\frac{k_{a}}{\rho_{a} C_{a}}, \beta=\frac{1}{T_{f}}$,

Overall glass heat loss coefficient $\left(U_{t}\right)$ : is the heat loss coefficient from glass cover to ambient due to combined effect of convention by wind and radiative heat transfer from glass cove to the sky:

$$
U_{t}=h_{c, g-\text { wind }}+h_{r, g-s k y}
$$

Convective heat transfer coefficient from glass cover to the wind: Convective heat transfer coefficient to the ambient is the major heat lost parameter in solar chimney system. The correlation depends on the features like wind direction and average wind speed, this coefficient has the following form for a windward and leeward surface principles to our problem area:

$$
h c, g-\text { wind }=5.7+3.8 \mathrm{~V}
$$

Radiative heat transfer coefficients between glazing and to the sky: The radiation heat transfer coefficient from the top glass surface to the sky referred to the ambient temperature is obtained:

$$
h_{r, g-s k y}=\sigma\left(T_{g}+T_{s k y}\right)\left(T_{g}{ }^{2}+T_{s k y}{ }^{2}\right)\left(\frac{T_{g}-T_{s k y}}{T_{g}-T_{a m b}}\right)
$$

Radiative heat transfer coefficients from absorber wall to glass cover: the coefficient of radiation heat transfer between absorber wall and glass cover may be obtained from the following equation:

$$
\mathrm{h}_{r . w-g}=\frac{\sigma\left(T_{w}{ }^{2}+T_{g}{ }^{2}\right)\left(T_{w}-T_{g}\right)}{\frac{1}{\varepsilon_{G}}+\frac{1}{\varepsilon_{w}}-1}
$$

Solar irradiation: so as to locate the solar energy vitality falling on a surface having any direction, it is important to change over the incentive from the sun to a proportional relating to the ordinary surface. The total solar radiation is the sum of beam, diffuse and reflected from the ground and the surrounding on a surface. according to Gosh and Tiwari (2008), the radiation heat flux absorbed by the blackened absorber wall is given by:

$$
S_{w}=A_{w} \tau_{g} \alpha_{w} I
$$

And solar radiation heat flux absorbed by the glass cover is given by: 


$$
S_{g}=A_{g} \alpha_{w} I
$$

The declination, $\delta$ : Cooper has given the connection for the declination through conditions, for given day of the year as follows.

$$
\delta=23.45^{\circ} \sin \left[\frac{360}{365}(284+d)\right]
$$

Instantaneous efficiency: The instantaneous efficiency of the chimney, $\eta_{i}$ can then be deduced as: desire output / required input or Energy Output / Energy Input,

$$
\eta_{i}=\left(\frac{M * C_{f} *\left(T_{o u t}-T_{r}\right)}{I * L * H}\right) * 100
$$

Energy input $=$ Solar insolation data, $I=Q_{\text {in }}(k w)$

Energy output $=$ Mass flow rate $\mathrm{x}$ Specific heat of air $\mathrm{x}$ Difference in Temperature $(k w)$

$$
Q_{\text {out }}=\dot{m} \times \operatorname{Cp} \times\left(T_{\text {out }}-T_{r}\right)
$$

Then the chimney outlet temperature and air change per hour expressed as:

$$
T_{\text {out }}=T_{r}+\frac{Q_{\text {out }}}{\dot{m} c_{p}}
$$

$$
A C H=\frac{3600 \times Q_{V}}{\text { Total Volume }}=\frac{3600 \times \frac{\dot{m}}{\rho_{f, o}}}{\text { Vol }}
$$

Number of air change rate per hour also called Air changes per hour is a measure of the amount air removed from a space divided by the volume of the space. It can be determined from volumetric flow rate using the equation below.

\section{Result and Discussion}

The simulation was employed to optimize the parameters of solar chimney length (L), cavity width (W) and height (Ha), to calculate temperature of glass, absorber wall and cavity air temperature, mass flow rate or ventilation rate and to predict instantaneous thermal performance according to actual Bahir Dar weather data and taking reference values for solar chimney from proposed villa house as length 1 up to $8 \mathrm{~m}$, cavity width 0.1 up to $0.5 \mathrm{~m}$ and height is $4.24 \mathrm{~m}$. Figure 6 , gives the monthly evolution of average solar radiation at Bahir Dar City. Note that the minimum of radiation is in July and August at an average solar intensity value $\mathrm{b} / \mathrm{n} 650 \mathrm{~W} / \mathrm{m}^{2}$ to $680 \mathrm{~W} / \mathrm{m}^{2}$ and the best solar radiation is in April and May with a value of approximately $900 \mathrm{~W} / \mathrm{m}^{2}$ for the year of 2013

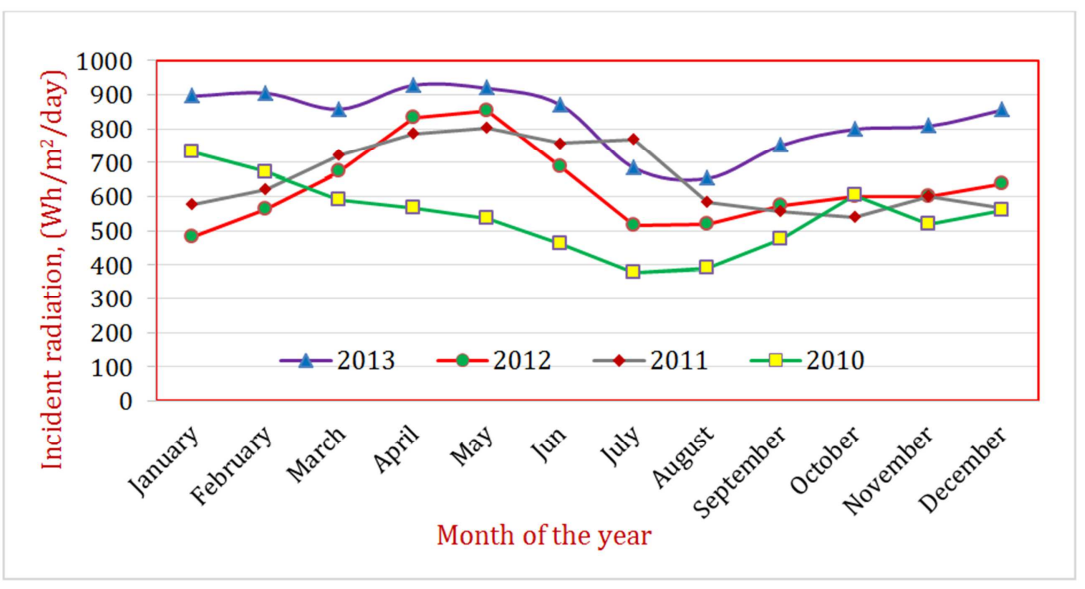

Figure 6. Monthly evolution of average solar radiation [for the year 2010-2013].

Figure 7, shows the results of mass flow rate for the different value of solar chimney width and then plot them with respect to the solar chimney length, from the graph conclude that mass flow rate increases when correspondingly increases the length and width of solar chimney. That means, Increasing the length means, having wide absorber surface and it can collect great amount of solar radiation.

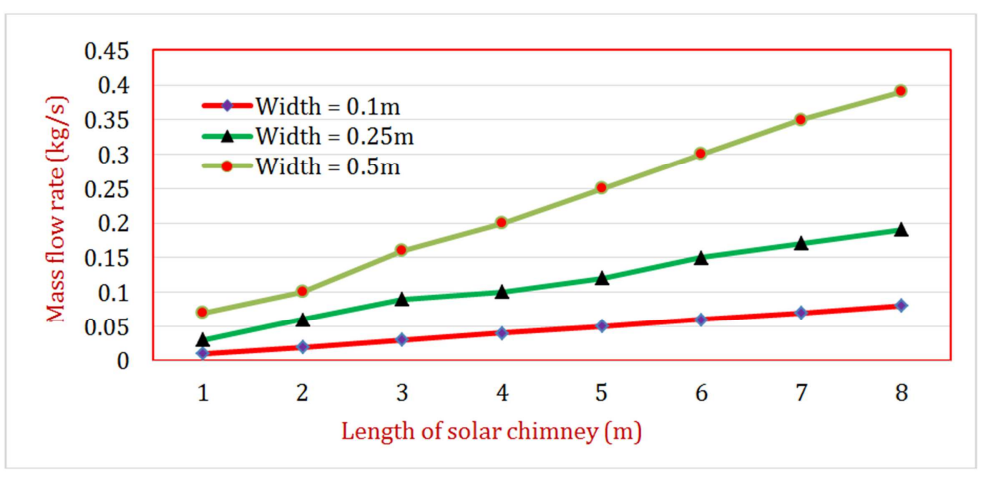

Figure 7. Mass flow rate (m) for different values of solar chimney length and width. 
Figure 8 , indicates that the volume flow rate for various values of solar chimney length and width, it is nothing but same as the result of mass flow rate and it is used to able to determine the air change rate $\mathrm{ACH}$ value and optimize solar chimney dimension, at which value the system attain high ventilation rate.

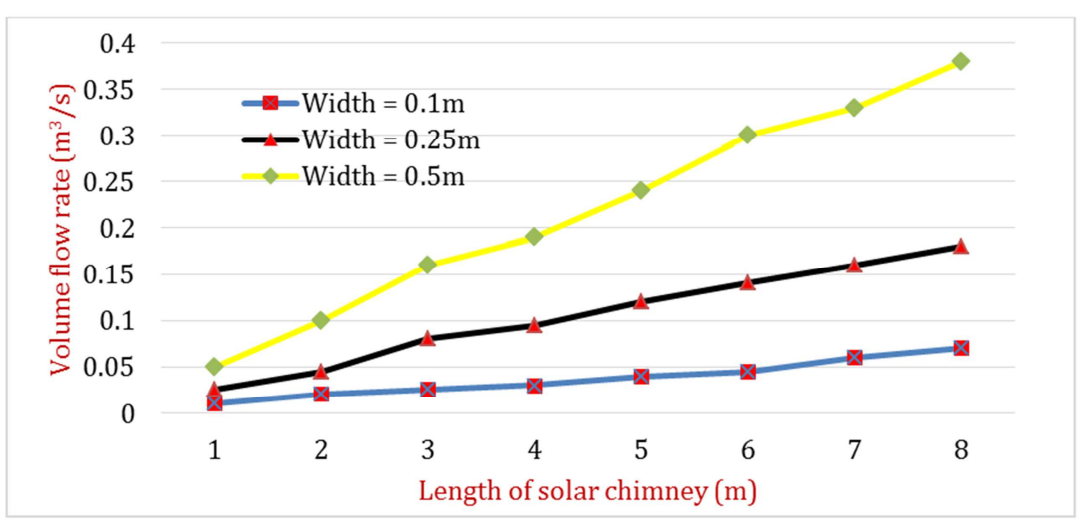

Figure 8. Volume flow rate ( $V$ ) for different values of solar chimney length and width.

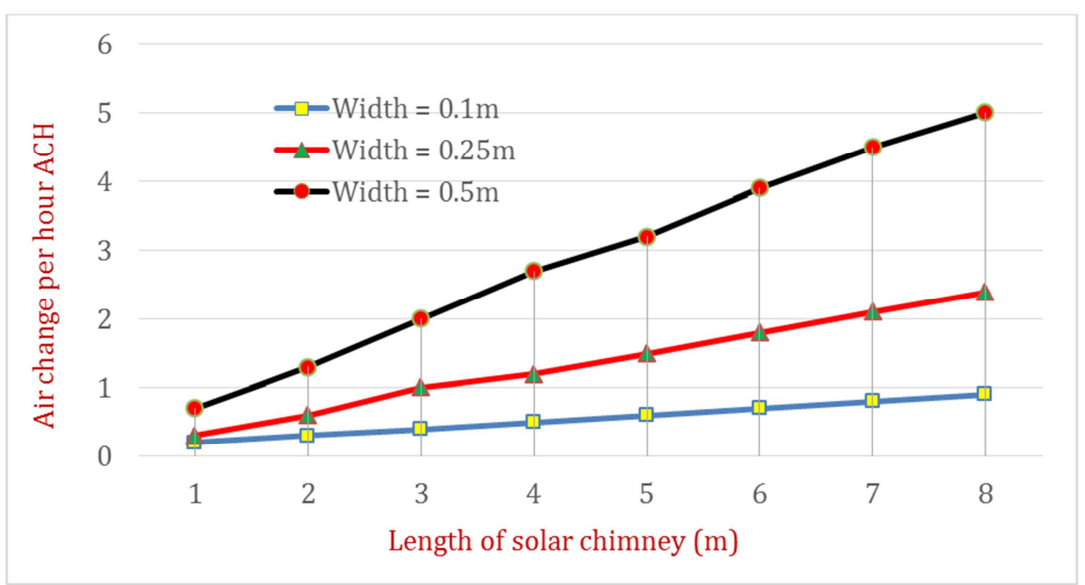

Figure 9. Air change rate (ACH) for different values of solar chimney length and width.

Figure 9, Shows the result of the volume of fresh air supplied for comfort ventilation, number of $\mathrm{ACH}$ within an hour for various solar chimney length and width values. The required size of the solar collector area for the solar chimney will optimize depend on the required air change rate in a house. because the air change rate affects the circulation and fresh oxygen supplied for human comfort.

In the case of this paper, spaces occupied by in levels of activities including kitchen service and toilet rather than low level of living house. For the type of spaces, according to Ethiopian building construction standard the possible value of $\mathrm{ACH}$ is between 1-2, by considering the worst case, taking the maximum ACH 2. From the graph, for the simulation we have three different possible solar chimney width values of 0.1 , 0.25 and $0.5 \mathrm{~m}$. and the length varies from $1 \mathrm{~m}$ up to $8 \mathrm{~m}$ respectively. However, at $\mathrm{ACH}$ of 2 to use the smallest width, it needs extended length of solar chimney more than the specified size of the roof. So, the best fit is smaller solar chimney length with higher width to give the maximum possible ventilation rate for the selected house type. At the value of ACH 2, the effective solar chimney length and width will be 3.042 and $0.5 \mathrm{~m}$ respectively. Figures 7 and 8 , introduces at length and width of 3.042 and $0.5 \mathrm{~m}$, the value of mass flow rate and volume flow rate will be: $0.1563 \mathrm{~kg} / \mathrm{s}$ and $0.1497 \mathrm{~m}^{3} / \mathrm{s}$, at absorber height and stack height of solar chimney of $4.24 \mathrm{~m}$ and $3.042 \mathrm{~m}$ respectively.

Figure 10, demonstrates, the variation of the air temperature at outlet with solar chimney length for various inlet heights (cavity width). It is seen that for the narrowest cavity depth = $0.1 \mathrm{~m}$ the air temperature at outlet varies only in small range between $28.8^{\circ} \mathrm{C}$ and $31.7^{\circ} \mathrm{C}$ so, hard to achieve the required temperature difference with the ambient. When the inlet height increases to $0.25 \mathrm{~m}$, the air temperature greatly from only $30.4^{\circ} \mathrm{C}$ to around $36.8^{\circ} \mathrm{C}$ and then shows some temperature reduction occurs at outlet, the reverse flow induces fresh air into the outlet that reduces the average air temperature. When the inlet height increases to $0.5 \mathrm{~m}$ and above the highest temperature $44.5^{\circ} \mathrm{C}$ is obtained at $3 \mathrm{~m}$ length. Due to the occurrence of the reverse flow at the outlet the temperature range curves down in small range after $3 \mathrm{~m}$. According to material cost and simplicity $0.5 \mathrm{~m}$ width, $3 \mathrm{~m}$ length and $4.24 \mathrm{~m}$ height is the effective dimension to obtain enough air temperature and suitable air velocity. 


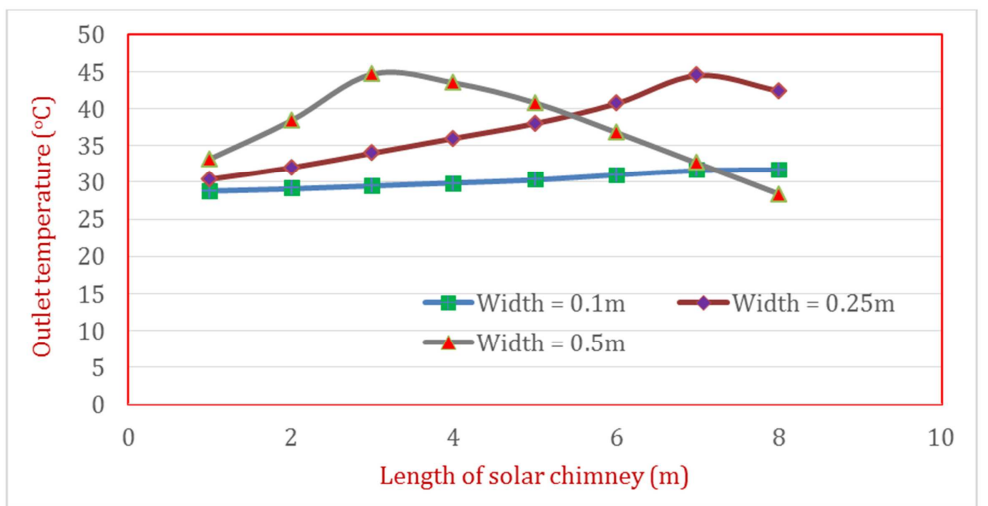

Figure 10. Solar chimney outlet temperature.

Figure 11, shows the annual ventilation performance profile of solar chimney model for three-years, solar radiation data at Bahir Dar city collected 2011 up to 2013. As seen in the figure, we note that the corresponding instantaneous solar chimney efficiency approximately about 44\% in April 2013, which indicates, their maximum corresponds to the maximum value of incident solar radiation. These parameters increase with the flow rate increasing following the absorber wall surface size.
It is demonstrated that the impact of the occurrence sun radiation is the significant parameter on vitality exhibitions examination of the chimney and an ideal structure of the sun-oriented stack length and the outside of the safeguard divider. Since Ethiopia has gotten incredible measure of sun radiation as appeared with three-year information, it is a decent consent to acknowledge the structure.

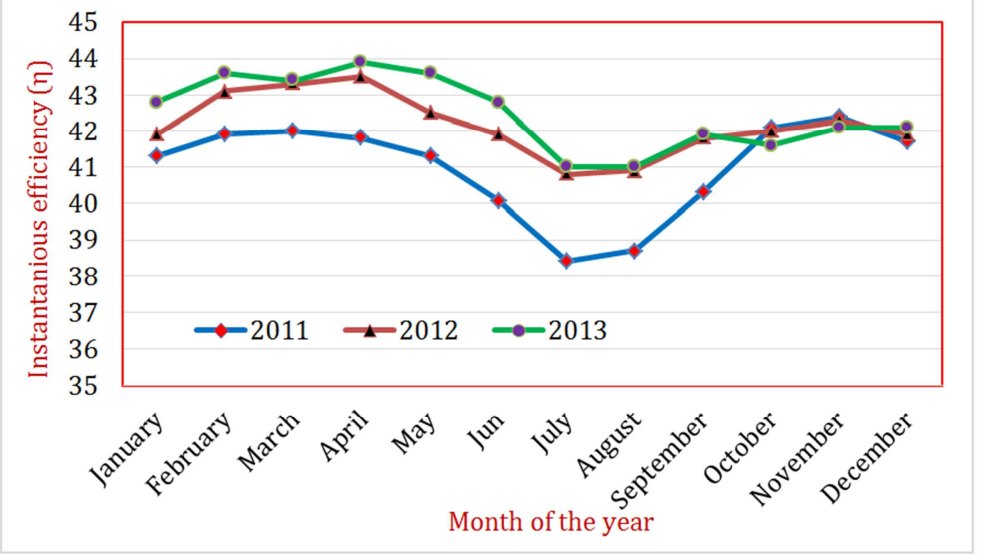

Figure 11. Efficiency of the system for annual average daily solar radiations throughout the year.

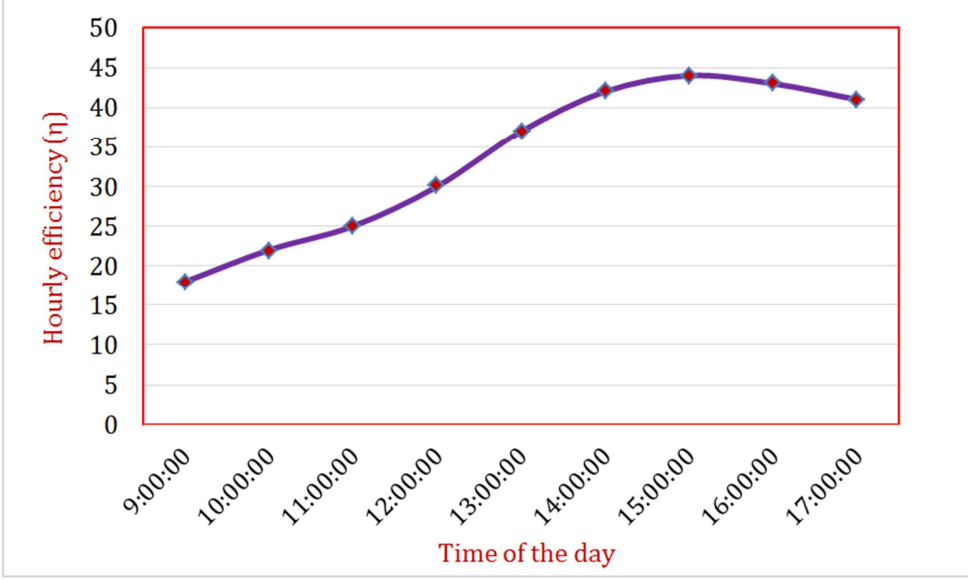

Figure 12. Hourly efficiency of solar chimney.

Figure 12, shows the daily efficiency profile of solar chimney system with respect to highest average hourly solar radiations intensity data for the month of April 2013. The useful daily sunshine hours in Bahir Dar city is $8 \mathrm{hrs}$, from the 
time frame of morning 09:00 am to 17:00 pm. As it is clearly shown in the Figure, the efficiency is increasing corresponding to increasing the time of the day and it becomes maximum at $14: 30 \mathrm{pm}$ to $16: 00 \mathrm{pm}$, then after it start drop due to falling of the strength of sun energy.

\section{Conclusion}

The corresponding instantaneous solar chimney efficiency is mainly influenced by the solar radiation intensity, solar chimney parameters. To improve the efficiency of the system, the temperature difference between the air inside the solar chimney cavity with the surrounding must be high and this comes from the solar radiation energy which heated up the absorber wall results to rise the temperature of the air. To have high temperature difference the length and height of solar chimney absorber must be increased or to increase the efficiency. Ventilation performance of solar chimney throughout the year, and daily efficiency profile varies due to the variation of solar radiation energy. In winter countries near to equator such as Ethiopia receives great amount of sun radiation. So, the efficiency reaches maximum while in summer, the efficiency will drop since solar radiation can directly influence the efficiency. Ventilation is achieved by buoyancy effects built in a roof to ventilate a residential house with a size of $264 \mathrm{~m}^{3}$, located at Bahir Dar Ethiopia. Top roof sloped solar chimney system where designed with keeping a recommended comfortable air change rate (air speed) for residential, the value selected for the house type is 2 and the size of the solar chimney absorber length, height and cavity width are optimized, the result is $3.042 \mathrm{~m}, 4.24 \mathrm{~m}$ and $0.5 \mathrm{~m}$ respectively one of the beauty of this system in easy to implement to existing buildings. All numerical calculations are done for the month of April and the value is $900 \mathrm{~W} / \mathrm{m}^{2}$. The mass flow rate and volumetric flow rate at the optimized parametric dimensions of solar chimney are $0.1563 \mathrm{~kg} / \mathrm{s}$ and $0.1497 \mathrm{~m}^{3} / \mathrm{s}$. And the system efficiency for the month of April is $44.4 \%$, but it is various with time and throughout the year because it is influential with the solar intensity. The proposed mathematical model of rooftop solar chimney enables better air circulation. This will significantly reduce energy bill; it is ecofriendly from economic analysis the system can save 227.03ETB per year.

\section{Future Work}

To improve the precision of the model for the purpose of residential passive ventilation the following matters should be considered in the future work. In this study one of the problems is that the system has not been assure to work with 24 hours, so transient analysis with some energy storage mechanism should study to improve the performance and allows keeping ventilation during part of the night. The study also not considered detail physical properties and using different solar chimney elements such as: different thermal mass materials, various absorber wall tilt angel and configuration. Also attaching an extension of sloped solar chimney on the roof of building needs further study to the appearance and aesthetic aspect.

\section{Acknowledgements}

I would like to thank National Meteorological Service of Ethiopia for their timely response to give some valuable environmental (Solar and wind) data, and appreciate my institution for the supports in simulation lab (MATLAB), materials and encouragements.

\section{Nomenclatures}

$\begin{array}{ll}C_{d} & \text { Discharge coefficient } \\ C_{f} & \text { Heat capacity of the fluid } \\ H a & \text { Absorber height of solar chimney }(\mathrm{m}) \\ h_{r, w_{-} g} & \text { Radiation wall - glass }\left(\mathrm{W} / \mathrm{m}^{2} \cdot K\right) \\ h_{r, g_{-} s k y} & \text { Radiative glazing - sky }\left(\mathrm{W} / \mathrm{m}^{2} \cdot K\right) \\ h_{c, g_{-} a} & \text { Convection b/n air - glass }\left(\mathrm{W} / \mathrm{m}^{2} \cdot K\right) \\ h_{c, w-r o o f} & \text { Conv. b/n wall - ceiling }\left(\mathrm{W} / \mathrm{m}^{2} \cdot K\right) \\ h_{c, g_{-} \text {wind }} & \text { Conv. b/n glass - ambient }\left(\mathrm{W} / \mathrm{m}^{2} \cdot K\right) \\ I_{h o r i z o n t a l}, & \text { Radiation on horizontal }\left(\mathrm{W} / \mathrm{m}^{2}\right) \\ I_{v e r t i c a l}, & \text { Radiation on vertical }\left(\mathrm{W} / \mathrm{m}^{2}\right) \\ q^{\prime \prime} & \text { Heat transfer to the flowing air stream } \\ \dot{m} & \text { Mass flow rate } \\ S_{g} & \text { Radiation on the glass cover }\left(\mathrm{W} / \mathrm{m}^{2}\right) \\ S_{w} & \text { Radiation on absorber wall }\left(\mathrm{W} / \mathrm{m}^{2}\right) \\ T_{a} & \text { Ambient temperature }(K) \\ T_{f} & \text { Temperature of air }(K) \\ T_{\infty} & \text { Surrounding temperature }(K) \\ T_{g} & \text { Glass cover temperature }(K) \\ T_{r} & \text { Room temperature enters chimney }(K) \\ T_{s} & \text { Temperature of air }(K) \\ T_{w} & \text { Wall temperature }(K) \\ T_{s k y} & \text { Sky temperature }(K) \\ & \end{array}$

\section{Greek Letter Symbols}

$\begin{array}{ll}\alpha_{w} & \text { Absorptivity of the wall } \\ \tau_{g} & \text { Transmitivity of the glass } \\ \phi & \text { Latitude angle } \\ \alpha & \text { Thermal diffusivity } \\ \beta & \text { Solar chimney slop angle } \\ \mu & \text { Dynamic viscosity }\end{array}$

\section{Subscripts}

$\begin{array}{ll}a & \text { Air } \\ c & \text { Flow coefficient, dimensionless } \\ c v & \text { Control volume }\end{array}$

\section{References}

[1] Afrooz Ravanfar. "Simulation study of solar chimney assisted solarium". (2003) Unpublished https://digital.library.ryerson.ca/islandora/object/RULA:2877 
[2] ASHRAE, S. 5. (2010.). Thermal Environmental Conditions for Human Occupancy, American Society of Heating, Refrigeration and Air Conditioning Engineers Inc.,. Atlanta. http://www.aicarr.org/Documents/Editoria_Libri/ASHRAE_P DF/STD55-2004.pdf

[3] J. Hirunlabh, S. Wachirapuwadon, N. Pratinthong and J. Khedari, New configurations of a roof solar collector maximizing natural ventilation. Building and Environment, 36 (3): 383-391 · April 2001. DOI: 10.1016/S0360-1323(00)00016-0

[4] Leticia Neves, Maurício Roriz and Fernando Marques da Silva "modeling a solar chimney for maximum solar irradiation and Maximum airflow, for low latitude locations". https://pdfs.semanticscholar.org/1166/8a0462fe9576d4f38615 c2ebaaaccec8eea8.pdf? ga $=2.50201891 .480476871 .15883495$ 53-776503668.1588349553

[5] A. G. Li and P. J. Jones, Developments in strategies used for natural and mechanical ventilation in China. Indoor and Built Environment, 9, 65-74 (2000).

[6] Ding, W., Hasemi, Y., \& Yamada, T. (2005). Natural ventilation performance of a double-skin façade with a solar chimney. Energy and Buildings, 37(4), 411-418. https://doi.org/10.1016/j.enbuild.2004.08.002

[7] Chungloo, M. A. and G. H. Limmeechokchai, 2008. The solar chimney overall effficiency, design and performance. Int. J. Ambient Energy, 8: 35-40

[8] SP 1609 - 1618. "Modelling of thermal behaviour of a direct solar drier possessing a chimney: Application to the drying of cassava". Indian Journal of Science and Technology Vol. 4 No. 12 (Dec 2011) ISSN: 0974- 6846 DOI: 10.17485/ijst/2011/v4i12/30294

[9] Gang Wang, Bing Chen, Mingsheng Liu, Joerg Henkel, Stephan Raulin. "Analysis, design, and preliminary testing of solar chimney for residential air-conditioning applications". $p$ roc. ASME. ISEC2004, Solar Energy, 291-297, July 11-14, 2004. Paper No: ISEC2004-65093 https://doi.org/10.1115/ISEC2004-65093

[10] M. N. Bahadori. "Viability of wind towers in achieving summer comfort in the hot-arid regions of the Middle East". Renewable Energy, Volume 5, Issues 5-8, August 1994, Pages 879-892. https://doi.org/10. 1016/0960-1481(94)90108-2

[11] K. B. Koua, P. Gbaha, E. P. M. Koffi, W. F. Fassinou and S. Toure. "Modelling of thermal behaviour of a direct solar drier possessing a chimney: Application to the drying of cassava". Indian Journal of Science and Technology Vol. 4 No. 12 (Dec 2011) ISSN: 0974- 6846

[12] A. M. Rodrigues A. Canha da Piedade A. Lahellec J. Y. Grandpeix. "Modeling natural convection in a heated vertical channel for room ventilation". Building and Environment Volume 35, Issue 5, 1 July 2000, Pages 455-469 https://doi.org/10.1016/S0360-1323(99)00027-X
[13] Hussain H. Al-Kayiem and Yit Man Heng. "Experimental investigation of rooftop solar chimney for natural ventilation". ARPN Journal of Engineering and Applied Sciences VOL. 10, NO 21, NOVEMBER, 2015 ISSN 1819-6608

[14] Shiv Lal, Kaushik C., Bhargava P. K. "Solar Chimney: A Sustainable Approach for Ventilation and Building Space Conditioning". International journal for sustainable development, vol.2 issue 1 pp. 277-297, 2012, DOI: IJDS1211090

[15] Leila Moosavi n. Norhayati Mahyuddin. Norafida Ab Ghafar. Muhammad Azzam Ismail 2014. Thermal performance of atria: An overview of natural ventilation effective designs. https://doi.org/10.1016/j.rser.2014.02.035

[16] Sandberg, M., \& Moshfegh, B. (2002). Buoyancy-induced air flow in photovoltaic facades: Effect of geometry of the air gap and location of solar cell modules. Building and Environment, 37 ,

211-218. http://dx.doi.org/10.1016/S0360-1323(01)00025-7

[17] Sarachitti, R.; Hirunlabh, J.; Khedari, J. 3-D modeling of solar chimney-based ventilation system for building. In Proceedings of the World Renewable Energy Congress VI, Brighton, UK, 1-7 July 2000; pp. 690-693.

[18] Leng Pau Chung, Mohd Hamdan Ahmad, Dilshan Remaz Ossen, Malsiah Hamid, Effective Solar Chimney Cross Section Ventilation Performance in Malaysia Terraced House. Volume 179 DO - 10.1016/j.sbspro.2015.02.431

[19] Li, Yongcai \& Liu, Shuli, 2014. "Experimental study on thermal performance of a solar chimney combined with PCM," Applied Energy, Elsevier, vol. 114 (C), pages 172-178.

\section{Biography}

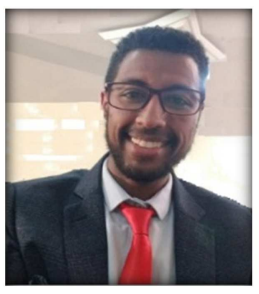

Tamerat Demeke is working with Debre Berhan University, department of Mechanical Engineering at Lecturer position. He received the MSc, degree in Thermal Engineering from Bahir Dar Institute of Technology, in 2015 and awarded his BSc. degree from Dire Dawa Institute of Technology in 2013. He proactively participates in community service and research activities, teaching learning and student advising throughout his work. He has presented 1 national conference and 2 seminar papers in the field Thermal Engineering. His areas of interests are Ventilation Systems, Combined Heating Cooling and Power Generation plant, thermal water purification, renewable energy and Computational Fluid Dynamics. 